\title{
PERANCANGAN VIRTUAL REALITY DALAM MENGETAHUI GEJALA ACROPHOBIA
}

\author{
Muhammad Fadli Prathama ${ }^{1}$, Dwina Kuswardani ${ }^{2}$, dan Andi Dahroni ${ }^{3}$ \\ ${ }^{1,2,3}$ Jurusan Teknik Informatika, STT PLN \\ E-mail:_fadli@sttpln.ac.id,dwina@sttpln.ac.id,andidahroni@sttpln.ac.id
}

\begin{abstract}
The most common phobia and most people in the entire world is Acrophobia fearing heights, there are about $23 \%$ of the population stating that they are afraid of heights. Acrophobia sufferers will always look anxious and in a panic where the closest people need to be around to calm down. Excessive fear of anything is generally not good because it can hinder daily activities.

So from that it is necessary to know the symptoms of acrophobia sufferers for the surrounding community to be able to take action to calm sufferers when sufferers of acrophobia relapse. The results of this study are expected to create a virtual reality-based software prototype to help people better recognize the symptoms of acrophobia sufferers. Researchers sincerely hope that the results of this study more or less provide benefits specifically for researchers and generally for all communities. In this study using the MDLC method in software development
\end{abstract}

Keywords: arcophobia, virtual reality, symptoms

\begin{abstract}
ABSTRAK
Fobia paling umum dan terbanyak di masyarakat seluruh dunia adalah Acrophobia takut ketinggian, ada sekitar $23 \%$ populasi menyatakan bahwa mereka takut akan ketinggian. Penderita acrophobia akan selalu terlihat cemas dan berada dalam kondisi panik di mana orang-orang terdekat perlu berada di sekitar untuk menenangkan. Ketakutan berlebih pada apa pun umumnya tidak baik lantaran hal tersebut bisa menghambat aktivitas sehari-hari.

Maka dari itu diperlukannya pengetahuan akan gejala para penderita acrophobia untuk masyarakat di sekitar agar dapat melakukan tindakan untuk menenangkan penderita disaat penderita acrophobia kambuh. Hasil penelitian ini diharapkan akan tercipta sebuah purwarupa software berbasis virtual reality untuk membantu masyarakat lebih mengenal gejala para penderita acrophobia. Peneliti sangat berharap hasil penelitian ini sedikit banyaknya memberi manfaat khususnya bagi peneliti dan umumnya bagi semua masyarakat. Pada penelitian ini menggunakan metode MDLC dalam pengembangan perangkat lunak
\end{abstract}

Kata kunci: acrophobia, virtual reality, gejala 


\section{PENDAHULUAN}

Manusia merupakan ciptaan Tuhan yang terbaik jika dibandingkan dengan mahluk lainya. Namun pada diri manusia selalu ada perasaan atau respon yang tidak menyenangkan terhadap sesuatu atau fenomena. Perasaan ini biasa disebut dengan fobia [1]. Fobia dapat menghambat kehidupan orang yang mengidapnya. Setiap orang memiliki kemampuan untuk mengendalikan perasaan tidak menyenangkan atau fobia, akan tetapi ada beberapa orang yang sulit untuk mengendalikan perasaan takut tersebut. Penyebab orang yang tidak bisa mengendalikan rasa takut dapat disebabkan oleh suatu keadaan yang sangat ekstrem seperti trauma.

Menurut data yang dihasilkan pada survey YouGov [2], fobia paling umum dan terbanyak di masyarakat seluruh dunia adalah Acrophobia takut ketinggian, ada sekitar 23\% populasi menyatakan bahwa mereka takut akan ketinggian. Orang dengan fobia ini diketahui terlalu berlebihan dalam mengestimasi jarak vertikal. Mereka yang sering salah dalam melakukan perhitungan, terbukti lebih rentan mengalami phobia ketinggian. Meskipun takut tinggi tergolong normal, akan tetapi lambat laun penderita akan merasakan kerugian dari rasa takut yang dirasakannya terus-menerus itu. Menurut situs terapieft gejala yang ditimbulkan dari acrophobia, penderita akan mengalami beberapa gejala ketika dalam posisi ketinggian, seperti kepanikan yang luar biasa, sesak nafas, mata berkunang-kunang, mual, dan pada penderita akut bisa terjadi pingsan.

Menurut situs health liputan6 [3]. Ketakutan berlebih pada apa pun umumnya tidak baik lantaran hal tersebut bisa menghambat aktivitas sehari-hari. Jika tidak ada orang terdekat atau yang paham akan kondisi tersebut di sekitar penderita, maka sangat mungkin kondisinya bisa menjadi lebih buruk saat sendirian di tempat tinggi. Maka dari itu diperlukannya pengetahuan akan gejala para penderita acrophobia untuk orang-orang di sekitar agar dapat melakukan tindakan menenangkan disaat penderita acrophobia kambuh.

Hasil observasi yang sudah dilakukan penulis adalah dengan menyebarkan kuesioner kepada para penderita acrophobia. Kesimpulan dari hasil observasi di dapat bahwa para penderita sebenarnya selain membutuhkan terapi untuk kesembuhan phobia namun ada hal yang dirasa juga penting, yaitu dengan mengedukasi orang lain yang tidak memiliki phobia yang sama agar dapat lebih menghargai para penderita, karena phobia ini kadang dimanfaatkan untuk bahan lelucon. Hasil wawancara dengan penderita acrophobia mengungkapkan bahwa untuk mengedukasi orang lain akan sakit yang dirasakan adalah dengan cara mencoba menjelaskan secara rinci apa yang dirasakan oleh penderita, atau mencoba untuk memvisualisasikan pengalaman yang terjadi ketika sedang dalam keadaan phobia.

Virtual Reality merupakan sebuah teknologi yang membuat pengguna atau user dapat berinteraksi dengan lingkungan yang ada dalam dunia maya yang disimulaiskan oleh komputer, sehingga pengguna merasa berada dalam lingkungan tersebut [4]. Tujuan dari virtual reality adalah untuk mencapai rasa yang kuat berada pada lingkungan maya. Untuk memunculkan sensasi nyata dari virtual reality diperlukan perangkat pendukung. Perangkat yang digunakan untuk mendukung teknologi virtual reality biasanya berupa headseat, suit, helm dan sarung tangan. Perangkat tersebut bertujuan untuk melibatkan sebanyak mungkin indra yang dimiliki manusia. Dengan banyak indra yang terlibat dalam virtual reality akan berbanding menambah tingkat sensasi nyata dari dunia virtual yang dimunculkan.

Mengacu pada latar belakang diatas, maka penelitian ini diberi judul "PERANCANGAN VIRTUAL REALITY DALAM MENGETAHUI GEJALA ACROPHOBIA”

\subsection{Arcophobia}

Menurut Manual Diagnostik dan Statistik Mental Gangguan, Edisi Keempat (DSM-IV) [5], acrophobia, yang mana adalah ketakutan yang ekstrim akan ketinggian, dianggap sebagai fobia spesifik tipe naturalistik meski sudah lama dikenal sebagai kelainan, masih ada beberapa keraguan tentang tipologi karena kesamaannya dengan baik gangguan panik [6] dan agoraphobia [7]. Acrophobia nampak terkait erat dengan ketakutan lift dan ketakutan terbang, keduanya termasuk dalam fobia spesifik, tipe situasional, yang didefinisikan dalam DSM-IV [8]. Perilaku akrofobik biasanya melibatkan penghindaran variasi situasi yang berhubungan dengan ketinggian, termasuk tangga, teras, apartemen dan kantor yang berada di gedung tinggi, jembatan, lift dan pesawat 
terbang perjalanan. Mengingat luasnya situasi yang tidak menyenangkan dan rangsangan, tidak mengherankan bila individu dengan acrophobia merasa terganggu dan dibatasi dalam gerakan mereka, bahkan jika dibandingkan penderita fobia spesifik lainnya [7]

\subsection{Pengertian Acrophobia Virtual Reality}

Dikutip dari situs codepolitan, Virtual reality adalah sebuah teknologi yang membuat pengguna atau user dapat berinteraksi dengan lingkungan yang ada dalam dunia maya yang disimulasikan oleh komputer, sehingga pengguna merasa berada di dalam lingkungan tersebut [4]. Di dalam bahasa Indonesia virtual reality dikenal dengan istilah realitas maya

Virtual reality memiliki kelebihan terutama dalam membuat user merasakan sensasi nyata di dalam dunia maya. Bahkan menurut situs codepolitan perkembangan teknologi virtual reality saat ini memungkinkan tidak hanya indra penglihatan dan pendengaran saja yang bisa merasakan sensasi nyata dari dunia maya dalam menggunakan virtual reality, namun juga indra yang lainya. [4]

\subsection{Metode Pengembangan Virtual Reality}

Metode dalam pembuatan virtual reality diantaranya:

\subsubsection{Simulation based VR}

Metode pertama adalah simulasi berbasis virtual reality. Simulator mengemudi, misalnya, memberi kesan pada pengemudi bahwa dia benar-benar mengendarai kendaraan yang sebenarnya dengan memprediksi gerak kendaraan yang disebabkan oleh masukan pengemudi dan memberi isyarat isyarat visual, gerak, audio dan proprioseptif yang sesuai kepada pengemudi. Simulator biasanya terdiri dari beberapa sistem sebagai berikut: sistem simulasi kendaraan real-time yang melakukan simulasi real time dinamika kendaraan; gerak, sistem visual dan audio yang mereproduksi gerak kendaraan, adegan lingkungan berkendara dan kebisingan yang dirasakan oleh pengemudi saat mengemudi; sebuah sistem penggerak jalan kendali yang bertindak sebagai penghubung antara pengemudi dan simulator; sebuah konsol operator untuk memantau operasi sistem; dan integrasi sistem pengelolaan informasi dan transfer data antar subsistem dan sinkronisasi. Simulator penggerak telah digunakan secara efektif untuk pengembangan sistem kendaraan, perbaikan keselamatan dan studi faktor manusia.

\subsubsection{Avatar Image Based VR}

Dengan realitas virtual berbasis gambar avatar, orang bisa bergabung dengan lingkungan virtual berupa video nyata sekaligus sebagai avatar. Sistem VR yang diusulkan dapat menangani dua tipe pengguna. Seseorang dapat berpartisipasi dalam lingkungan virtual terdistribusi 3D sebagai bentuk avatar biasa atau video nyata. Latar belakang video dieliminasi secara efektif untuk meningkatkan rasa realitas. Seorang pengguna dapat memilih jenis partisipasinya sendiri berdasarkan kemampuan sistem. Pengguna dengan papan tangkap dan kamera dapat memilih avatar video sementara yang lain memilih avatar berbasis grafis komputer konvensional. Avatar berbasis gambar VR sekarang menyediakan lingkungan interaksi yang cukup bagus antara manusia dan komputer jauh melampaui sistem komputer desktop konvensional. Jaringan berkecepatan tinggi tersedia dengan kemajuan teknologi jaringan.

\subsubsection{Projector Based VR}

Dalam realitas virtual berbasis proyektor, pemodelan lingkungan nyata memainkan peran penting dalam berbagai aplikasi virtual reality, seperti navigasi robot, pemodelan konstruksi dan simulasi pesawat terbang. Sistem virtual reality berbasis gambar semakin populer di bidang grafis komputer dan juga komunitas penglihatan komputer. Alasannya adalah menyediakan realisme lebih dengan menggunakan foto gambar realistis dan prosedur pemodelannya agak sederhana. Dalam menghasilkan model yang realistis, penting untuk mendaftarkan data 3D yang diperoleh secara akurat. Biasanya, kamera digunakan untuk memodelkan benda kecil pada jarak dekat. 


\subsubsection{Dekstop Based VR}

Realitas virtual berbasis desktop melibatkan tampilan dunia maya 3 dimensi pada layar desktop biasa tanpa menggunakan peralatan pelacakan gerakan khusus. Banyak permainan komputer modern dapat digunakan sebagai contoh, menggunakan berbagai pemicu, karakter responsif, dan perangkat interaktif lainnya untuk membuat pengguna merasa seolah-olah berada di dunia maya. Kritik umum dari bentuk perendaman ini adalah bahwa tidak ada penglihatan periferal, yang membatasi kemampuan pengguna untuk mengetahui apa yang terjadi di sekitar mereka.

\subsubsection{Head Mounted Display Based VR}

Layar yang terpasang di kepala digunakan yang sepenuhnya menenggelamkan pengguna di dunia maya. Layar terpasang di kepala mencakup dua monitor OLED atau LCD beresolusi tinggi kecil yang memberikan gambar terpisah untuk setiap mata untuk grafis stereoskopis yang menghasilkan dunia maya 3 dimensi, audio binaural stereoskopis, pelacakan posisi real time dan rotasi selama 6 derajat gerakan, dan opsional. kontrol gerakan dengan umpan balik haptic untuk berinteraksi secara fisik dalam dunia maya secara intuitif dengan sedikit tanpa abstraksi.

\subsubsection{True Immersive virtual Reality}

Realitas virtual hipotetis sebagai immersive sebagai realitas konsensus. Kemungkinan besar diproduksi dengan menggunakan antarmuka otak-komputer. Tahap peralihan dapat diproduksi oleh "Ruang Virtual" menggunakan layar head-mounted dengan head tracking dan kontrol komputer pada gambar yang dipresentasikan pada helm.

\section{METODE PENELITIAN}

Metode pada penelitian ini dapat dilihat pada gambar 1 berikut



Gambar 1. Metodologi Penelitian

1. Identifikasi masalah

Pada tahapan identifikasi masalah ini dilakukan analisis-analisis terhadap masalah yang ada sehingga dapat terlihat kebutuhan apa saja yang di butuhkan.

2. Pengumpulan data

Pada langkah pengumpulan data ini, berdasarkan hasil dari menentukan kebutuhan dilakukanlah beberapa cara dalam pengumpulan data yang bertujuan untuk memenuhi kebutuhan-kebutuhan. Beberapa cara dalam pengumpulan data ini yaitu, studi literature dan observasi 


\section{JURNAL PETIR}

Vol. 12, No. 1, Maret 2019, P-ISSN 1978-9262, E-ISSN 2655-5018

3. Membuat perangkat lunak

Penerapan hasil perancangan perangkat lunak yang telah dibuat dengan mempertimbangkan kemudahan dalam berinteraksi dengan perangkat lunak. Pada pembangunan aplikasi ini menggunakan metodologi MDLC.

MDLC (Multimedia Development Life Cycle). Multimedia Development Life Cycle menurut Luther tahun 1994 dalam Sutopo 2012 [9], MDLC memiliki 6 tahap, yaitu : tahap concept, tahap design, tahap material collecting, tahap assembly, tahap testing, dan tahap distribution. Tahapan tersebut dapat dijelaskan sebagai berikut seperti pada gambar 2 .

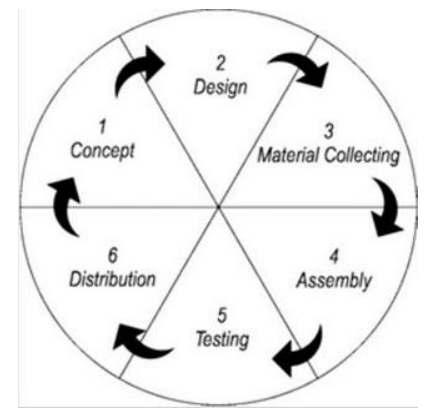

Gambar 2. Multimedia Development Life Cycle (MDLC)

\section{Concept}

Concept (konsep) adalah menentukan tujuan dan siapa pengguna program (identifikasi audience), macam aplikasi (presentasi, interaktif, dan lain-lain) dan spesifikasi umum.

2. Design

Design (perancangan) adalah membuat spesifikasi secara rinci mengenai arsitektur programs, storyboard, gaya tampilan dan kebutuhan material/bahan untuk program.

\section{Material Collecting}

Material Collecting (pengumpulan bahan) adalah tahap pengumpulan bahan yang sesuai dengan kebutuhan yang dikerjakan. Bahan-bahan tersebut, antara lain gambar clip art, foto, animasi 3D, video, audio, dan lain-lain.

4. Assembly

Tahap assembly (pembuatan) adalah tahap pembuatan semua objek atau bahan multimedia. Pembuatan aplikasi bagan alir (flowchart), dan struktur navigasi yang berasal pada tahap design.

5. Testing

Tahap testing (pengujian) dilakukan setelah menyelesaikan tahap pembuatan (assembly) dengan menjalankan aplikasi /program dan dilihat apakah ada kesalahan atau tidak. Tahap pertama pada tahap ini disebut juga sebagai tahap pengujian alpha (alpha test) yang pengujiannya dilakukan oleh pembuat atau lingkungan pembuatnya sendiri. Setelah lolos dari pengujian alpha, pengujian beta yang melibatkan pengguna akhir akan dilakukan.

6. Distribution

Tahap distribution aplikasi akan disimpan dalam suatu media penyimpanan. Tahap distribution juga dapat disebut tahap evaluasi untuk pengembangan produk agar menjadi lebih baik.

\section{HASIL DAN PEMBAHASAN}

\section{a. Konsep (concept)}

Konsep merupakan bagian vital dari aplikasi yang akan dibangun, karena pada bagian ini akan melakukan analisa dari data yang telah didapat dan menentukan spesifikasi dari aplikasi secara garis besar 


\section{b. Perancangan (design)}

Dalam proses perancangan terdapat beberapa tahapan-tahapan yang dilakukan yaitu dari mulai storyboard

\section{TABEL 1. STORYBOARD AWAL}

\begin{tabular}{|c|c|}
\hline \multicolumn{2}{|l|}{ ID Scene : Scene 001} \\
\hline \multicolumn{2}{|l|}{ Nama Scene: Scene 1} \\
\hline Logo & $\begin{array}{l}\text { Descripsi Scene : scene ini muncul } \\
\text { pada permulaan aplikasi, terdapat } \\
\text { logo dari aplikasi virtual reality. }\end{array}$ \\
\hline Resolusi Display: HD & \\
\hline
\end{tabular}

TABEL 2. STORYBOARD SCENE 2

\begin{tabular}{|l|l|}
\hline \multicolumn{2}{|l|}{ ID Scene : Scene 002} \\
\hline Nama Scene : scene 2 & $\begin{array}{l}\text { Descripsi Scene : menu utama } \\
\text { pada aplikasi } \\
\text { Terdapat 3 buah tombol untuk } \\
\text { memilih tempat untuk simulasi }\end{array}$ \\
\hline Resolusi Display: HD $1280 \times 720$ & \\
\hline
\end{tabular}

TABEL 3. STORYBOARD SCENE 3

\begin{tabular}{|l|l|}
\hline ID Scene : Scene 003 & \multicolumn{2}{|l|}{\begin{tabular}{l} 
Descripsi Scene : Tamplian Virtual \\
Realaity \\
Nama Scene : scene 3 \\
\hline
\end{tabular}} \\
\hline $\begin{array}{l}\text { Diharuskan menggunakan alat } \\
\text { seperti cardboard untuk dapat } \\
\text { merasakan sensasi simulasi }\end{array}$ \\
\hline Resolusi Display : HD $1280 \times 720$ & \\
\hline
\end{tabular}




\section{c. Material Collecting}

Dalam pembuatan Virtual Reality acrophobia ini dibutuhkan komponen komponen seperti tombol, gambar dan Video. Berikut ini adalah daftar komponen-komponen pendukung dalam pembuatan aplikasi Virtual Reality ini.

\section{TABel 4. DAFTAR Video}

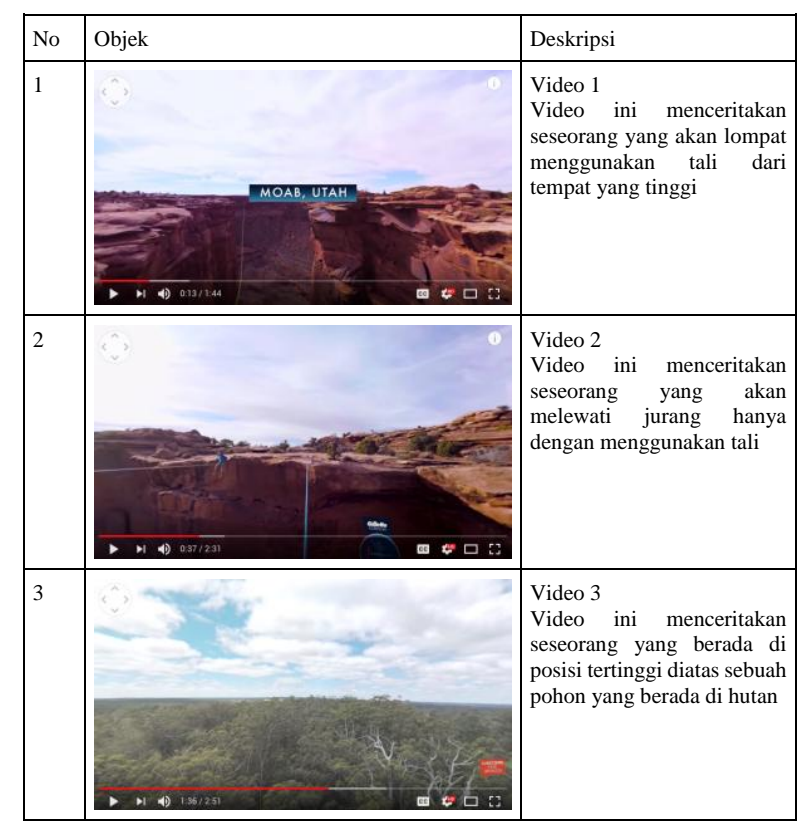

\section{d. Pengujian}

Aplikasi virtual reality diujikan pada 3 kandidat untuk dapat melihat respon masyarakat terhadap aplikasi virtual reality. Kandidat akan diukur detak jantung sebelum menggunakan aplikasi virtual reality dan sambil menggunakan aplikasi virtual reality
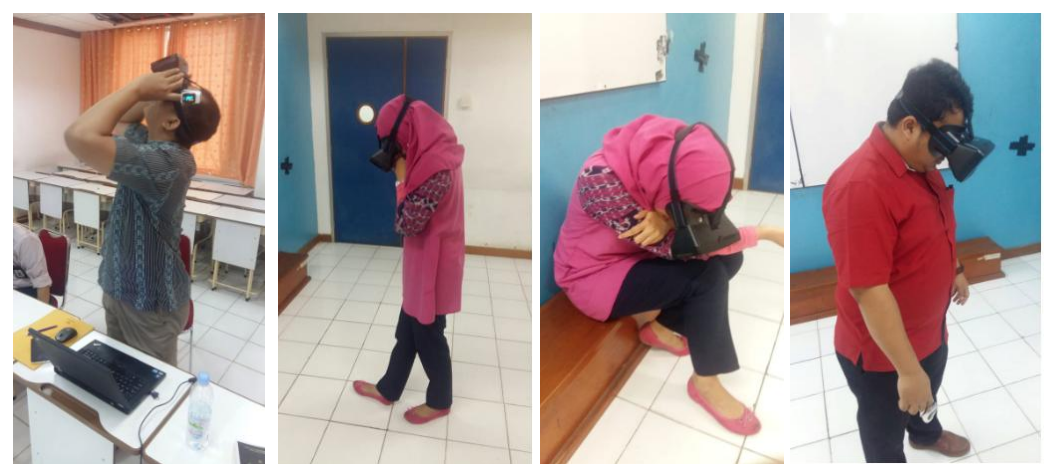

Gambar 2. Pengujian Virtual Reality

Berikut data denyut jantung dari ke 3 kandidat.

Tabel 5. Hasil Pengujian

\begin{tabular}{|c|l|c|c|c|}
\hline No & Nama & Video & Denyut Jantung awal & $\begin{array}{c}\text { Denyut jantung } \\
\text { akhir }\end{array}$ \\
\hline 1 & Eka Putra & 2 & $85 \mathrm{bpm}$ & $112 \mathrm{bpm}$ \\
\hline 2 & Pritasari & 2 & $82 \mathrm{bpm}$ & $122 \mathrm{bpm}$ \\
\hline 3 & Satrio Yudho & 2 & $84 \mathrm{bpm}$ & $90 \mathrm{bpm}$ \\
\hline
\end{tabular}

99| Jurnal PETIR 
Dapat dilihat dari hasil pengujian diatas denyut jantung meningkat ketika penggunaan aplikasi virtual reality, maka dari itu dapat di simpulkan bahwa tingkat stress seseorang dapat dirasakan oleh orang lain ketika menggunakan aplikasi virtual reality.

\section{KESIMPULAN DAN SARAN}

Penelitian ini dibuat dalam rangka membantu warga masyarakat mengenai gejala acrophobia. Dengan dibuatnya sebuah perangkat aplikasi virtual reality, pengguna akan lebih mudah memahami informasi yang disampaikan. Hasil dari penelitian ini diharapkan akan dapat menumbuhkan rasa kepedulian masyarakat terhadap para penderita acrophobia. Penelitian ini dirasa masih perlu dikembangkan kedalam tahapan terapi untuk menyembuhkan penderita Acrophobia.

\section{DAFTAR PUSTAKA}

[1] W. F. Maramis, Ilmu Kedokteran Jiwa, Surabaya: Airlangga University Press, 2009.

[2] W. Jordan, "Afraid of heights? You're not alone," 2003 2014. [Online]. Available: https://yougov.co.uk/topics/politics/articles-reports/2014/03/20/afraid-heights-not-alone. [Diakses 1012 2018].

[3] A. Pradita, "Cepat Sembuh dari Phobia Ketinggian dengan Cara Ini," 2402 2017. [Online]. Available: $\quad$ https://www.liputan6.com/health/read/2867057/cepat-sembuh-dari-phobiaketinggian-dengan-cara-ini. [Diakses 1012 2018].

[4] K. G. D. Herlangga, "Virtual Reality dan Perkembangannya," 0703 2016. [Online]. Available: https://www.codepolitan.com/virtual-reality-dan-perkembangannya. [Diakses 1012 2018].

[5] APA, Diagnostic and statistical manual of mental disorders (4th ed.), Washington, DC: American Psychiatric Association, 1994.

[6] M. B. T. A. \&. B. D. H. Antony, "Heterogeneity among specific phobia types in DSM-IV," Behaviour Research and Therapy, no. 35, pp. 1089-1100, 1997.

[7] G. C. L. M. R. \&. G. B. Davey, "Height phobia and biases in the interpretation of bodily sensations: some links between acrophobia and agoraphobia," Behaviour Research and Therapy, vol. II, no. 35, p. 997-1001, 1997.

[8] P. S. H. \&. M. H. Muris, "The structure of specific phobia symptoms among children and adolescents," Behaviour Research and Therapy, no. 37, p. 863-868, 1999.

[9] A. H. Sutopo, Multimedia Interaktif dan Flash., Yogyakarya: PT. Graha Ilmu, 2003.

[10] G. L. C. Davey, Phobias. A handbook of theory, research and treatment, Chichester: Wiley, 1997.

[11] B. \&. D. Whitten, Systems Analysis and Design Methods 6th Edition, Washington, America: McGraw-Hill, 2004. 